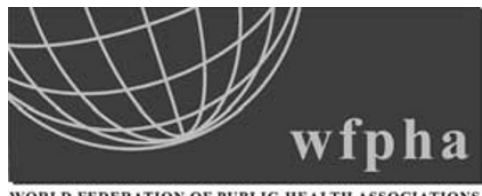

WORLD FEDERATION OF PUBL.IC HEALTH ASSOCIATIONS

\title{
WFPHA World Federation of Public Health Associations www.wfpha.org
}

Journal of Public Health Policy (2008) 29, 467-473. doi:10.1057/jphp.2008.36

\section{THE FEDERATION'S PAGES}

\section{Editorial: Global Health and Health Diplomacy}

The public health field has been confronted with an astounding amplification of health inequities both between and within developing countries. These differences in health outcomes are ethically and morally unacceptable, as they are caused by deliberate political, economic, and social actions, that is, they are socially determined.

This technical designation - "health inequities" - should be politicized, for it camouflages large humanitarian and social tragedies that take the lives of thousands of women and children, adolescents and young adults, who are thus deprived of the greatest good a human being can aspire to have: a long quality life. Hunger (and ensuing chronic under-nutrition and malnutrition), lack of drinking water, absence of minimum living conditions in general, and a deficit in rights and liberties yield a brief and hopeless life for many human beings.

The inherent unfairness of the circumstances of such inequities have been attracting the attention of the world because "concerted actions" of the global governance system - coordinated with the needs and proposals built by the countries themselves - have the potential to change sustainably most problems.

International donors have mobilized, cooperating with developing countries in the field of health through uni- and multilateral, multigovernmental, philanthropic or public-private arrangements that consume a considerable amount of resources. The dominant model of international aid, however, has been disease-focused, notwithstanding the fact that the

- Journal of Public Health Policy 2008, 29, 467-473 (C) 2008 Palgrave Macmillan 0197-5897/08 www.palgrave-journals.com/jphp/ 
true problem in most of these countries is not "a specific health problem" but the "health sector or system" or, sometimes, the society as a whole.

Thus, despite the billions of dollars and euros invested, such expenses have often turned out to be ineffective, in the sense that they have not been able to improve health conditions and the quality of life in developing countries. They focus only on a few specific problems and do not contribute to repelling its "systemic" and foundational causes, which are their true source. In response to the global health crisis - which has deeply interconnected economic, social, environmental, sanitary, educational, humanitarian and governance dimensions, and is not centered around a single problem or situation - donors usually focus on one specific problem (HIV/AIDS, for instance) and/or on one specific region or country. This focalized approach (both thematically and geographically) often takes place without coordination with existing national health plans, leading to further disarray health systems in aid-receiving countries.

One of the few comprehensive and intersectorial initiatives, the Millennium Development Goals, focuses simultaneously on poverty reduction, health, education, the environment, and gender issues. But despite the agreement established by nations at the United Nations' Millennium Summit, in 2000, developed countries have not contributed the resources they had committed to meet the objectives.

Not only are receiving countries not free of health needs, but also their links between the health and external relations sectors for the development of international cooperation programs are insufficient or nonexistent. Due to the enormous needs of their health systems, these countries often accept foreign aid formulated from the perspective of donor countries, which might bear little relation to ongoing national health plans. Thus, to improve international aid and cooperation in health, changes must be made in both perspectives: the donors' and multilateral agencies' and that of receiving countries.

International donors should harmonize their policies and projects, organizing discussion rounds among themselves and receiving countries so that "cooperation programs" (and not simply "projects") are defined. They can thus avoid disease-focused initiatives, instead supporting development of the countries' social protection and health systems. They should, moreover, coordinate "intersectorial" aid initiatives, not only those restricted to the health field, but also focused on health and its social determinants and not only specific problems or health as an isolated sector. 
Receiving countries should strengthen intersectorial bonds and bonds with the external relations sector to put forward a comprehensive agenda that can tackle problems in their health and social protection sectors globally.

In this way, global governance systems will develop fundamental tools in what might be called "health diplomacy," tools capable of implementing global health and reducing today's unacceptable health inequities.

The World Federation of Public Health Associations sounds this alarm and joins efforts to create a fairer and more egalitarian global society capable of promoting peace and prosperity worldwide.

Prof. Paulo Marchiori Buss, MD, MPH

President of the World Federation of Public Health Associations (WFPHA)

Professor of the National School of Public Health

President of the Oswaldo Cruz Foundation (FIOCRUZ, Brazil)

Full Member of the Brazilian National Academy of Medicine

E-mail: buss@fiocruz.br

\section{PUBLIC HEALTH AROUND THE WORLD}

Public Health Executive Agency (PHEA)

of the European Commission and Forum for Public Health

in South Eastern Europe (FPH-SEE):

Conference on Professionalisation and Capacity Building in Public

Health in South-Eastern and Eastern Europe:

The Legal and Educational Framework

Luxembourg, 20/21 February 2008

\section{Background}

As a consequence of its inclusion in the EU Treaty (art.129 of the Maastricht Treaty and later art. 152 of the Amsterdam Treaty), public health is rapidly gaining prominence in European public policy domains. The increasing importance of preparedness for major health threats, the growing recognition of health as an important resource for economic growth and sustainability, and the rising awareness that important health inequalities in Europe are powerful driving forces.

Still many EU Member States and Candidate Countries have insufficient institutional and professional capacity for public health. Their process of 
reforming the relevant services is slow. Compared to the USA, other industrialized countries, and a few emerging economies such as Brazil, the relative lack of public health capacity in the EU is striking. The field of public health is at a crossroads, compounding the problems. Referred to as the "Third Public Health Revolution", public health is undergoing profound changes:

Goals: from the reduction of disease and mortality to the increase of healthy life years and reduction of health inequalities.

Approach: from a top-down prescriptive, administrative approach based on a knowledge transfer model to a participatory approach characterized by multi-component solutions addressing multiple causes at the socio-economic, environmental, and individual levels. Actors: professional experts and decision makers are no longer the only relevant actors in dealing with population health, but are joined by a multi-disciplinary group including researchers, institutional decision-makers, professionals, civil society, and the private sector.

\section{Recommendations}

(1) Strategic Framework for capacity Building

1. Public Health capacities should be health oriented rather than disease oriented.

2. It is important to develop a strategic plan for capacity building for public health in Europe, starting from a SWOT analysis and defining specific capacity building objectives and targets.

3. Targets for a strategy to strengthen public health capacity should cover all five areas of current conceptual models of public health capacity building:

Organizational development,

Resource allocation,

Workforce development,

Partnerships,

Leadership.

4. Workforce development should be considered the highest priority, but other capacity areas/problems need to be developed/solved. 
5. Perspectives and expectations of public health from other sectors and policy areas should enrich capacity building and lay out a basis for health in all policies.

6. A "Public Health Identity" needs to be constructed, reflecting the diversification of professional functions in public health while reconciling them as they are shared.

7. Develop an EU Framework of public health competencies.

8. The strategy for capacity building in public health needs to consider horizontal and vertical aspects: it must address all levels of government and administration (supranational to local), all domains (private, civil society, public, etc).

9. The pace of strategy development for capacity building must fit with the national context, proceeding in a measured way.

10. The EU needs clear leadership in public health.

(2) Legal and organizational framework

1. Common law can provide a general framework for public health, while specific laws can cover more specific and practical issues-public health functions to services. The decision on the necessity to have common laws, however, lies with the Member States.

2. There should be a division of responsibilities and roles in public health functions between higher and lower levels of authorities. The State, centrally, should deal with legal issues of public health, for example, quality improvement for health or health reporting to international organizations. Public health policy formulation, standard setting and the main regulatory tasks should also remain at the national level. Specific aspects, as in environmental protection should be at the local level. Budgeting for public health actions should obligatory at all levels. Civil society and the community can support good governance for the public health at the state level. If a Bismarckian model is the main model of health care financing, health insurance entities should bear responsibility for public health as well.

3. The connections between academic institutions and public health institutions, and between research and preventive interventions should be strengthened, for example, to decide on interventions on the basis of cost-effectiveness studies. 
4. Individual health care is the responsibility of health care services (including different specialists in preventive programs such as immunizations, early detection of diseases, etc). Public health should be responsible for managing, monitoring, and reporting health services data on quality and efficiency focused on population-based approach.

5. There is a need to advocate more widely for population health, and particularly for ways to address social and economic determinants of health, and to bridge the gap between different sectors that are important for public health. Health information management and continuous quality improvement must be emphasized as core elements of the new public health.

6. There is a need for careful planning of human resources for public health at national and local level. Staffing and institutional policy in public health should become more integrated. Professional development of public health staff needs to be attended to, including incentives schemes for staff.

7. The EU policy framework provides an important incentive to build organizational, legal, and institutional capacity for public health. Unlike other countries or entities, the EU has declared that public health is important and has defined the common principles and values of universal access, solidarity, and equity. EU legislation is also an important consideration in the process of harmonization of the basis for public health actions, in the sense that the legal framework on public health is part of the Acquis Communautaire.

\section{(3) Educational Framework}

1. Academic institutions providing training in public health face the challenge to integrate medicine and social sciences into public health studies.

2. The Bologna process provides a framework to reform the public health training curriculum. The majority of representatives of faculties from SEE countries have already started or are preparing programs fully compatible with the Bologna process (BMD-three layer system allowing mobility among fields).

3. Public health topics, views, and experiences should be included in medical studies and placed in the curriculum from the very 
beginning. A $10 \%-15 \%$ proportion of the overall teaching should become a target.

4. Public health curricula need continuous improvement according to needs, they should come in modular format, offering major/ minor choices.

5. Research methodology should be taught from the first cycle (undergraduate or bachelor level) onwards, and further theory and practice be integrated in the curriculum. Requirements for faculty members should be of highest level of teaching and scientific/research competency.

6. Intra and interuniversity cooperation is crucial in organizing public health studies and should be facilitated within universities, at national and international level.

7. Public health programs should be organized as academic programs with all three Bologna cycles. They are not in competition with lifelong learning and professional training.

\section{Contact:}

Prof. Ulrich Laaser MD, DTM\&H, MPH

President elect of the World Federation of Public Health Associations (WFPHA)

Principal investigator of the Forum for Public Health in South Eastern Europe (FPH-SEE)

C/o University of Bielefeld

PO Box 100131

D-33501 Bielefeld, Germany

E-mail: ulrich.laaser@uni-bielefeld.de - www.snz.hr/fph-see 